\title{
Intelligent Control Strategy to Enhance Power Smoothing of Renewable based Microgrid with Hybrid Energy Storage
}

\author{
Yashwant Joshi ${ }^{a}$, Jai Kumar Maherchandani ${ }^{\text {, }}$, Raghuveer Raj Joshic, Vinod Kumar Yadav \\ a, b, c, d Department of Electrical Engineering \\ a, b, c, d College of Technology and Engineering, MPUAT, Udaipur, Rajasthan, India 313001 \\ Email id: yshwntjoshi@gmail.com
}

Article History: Received: 10 January 2021; Revised: 12 February 2021; Accepted: 27 March 2021; Published online: 20 April 2021

\begin{abstract}
A stand-alone renewable based microgrid (MG) performance with a hybrid energy storage system has been examined in this work. Stand-alone MG system mainly consists of a solar photovoltaic (PV) and permanent magnet synchronous generator (PMSG) based wind system. The hybrid energy storage system is based on Ni-Metal- Hydride (NiMH) battery and a supercapacitor (SC). The paper's primary goal is to propose an artificial neural network (ANN) based control strategy for charging/discharging control of Ni-Metal- Hydride battery \& supercapacitor. The proposed maximum power tracking techniques (MPPT) include perturb and observe (P\& O) algorithm for solar PV system while optimum torque (OT) MPPT for PMSG based wind turbine. The ANN-based control mechanism can maintain the DC bus voltage constant and trigger the supercapacitor to limit the battery current when the battery charging/ discharging current reached its threshold value. The proposed model responds quickly to intermittent nature PV-wind power generation or load power variation.
\end{abstract}

Index term: Artificial neural network, battery, control strategy, hybrid energy storage, microgrid, photovoltaic, supercapacitor

\section{Introduction}

A lot of research has been done on stand-alone hybrid microgrid (MG) with the energy storage system in a decade. Solar and wind renewable energy sources (RES) are widely used due to their availability and environmental benefits. The MG's have two operating modes, specifically, grid integrated and stand-alone modes. During the stand-alone mode of MG principal objective of a storage system, it maintains a balance of energy [1]. The energy storage system's role is significant as the floating nature of RES's creates reliability, stability and power quality issue in MG. The MG with a hybrid storage system (HESS) is considered a viable solution for the mentioned issues. The battery/ supercapacitor is capable enough to mitigate the above-said problems and harness the energy generated of RES's [2].

An appropriate combination of an energy storage system with a stand-alone microgrid can remove the power fluctuation and improve the power quality and reliability of the system [3].

Typically, HESS consists of two complementary energy storage devices with a high energy density and the other with a high-power density. The device with high energy density and low power gives power control problems due to slow response time, while high power devices affect the storage system's life cycle. During load variation, HESS supplies transient high power to fulfil the load demand. The resultant pulse current substantially increases the battery's operating temperature, which reduces battery life and efficiency of the system. The addition of secondary storage to the primary storage system can improve the life cycle and working condition and satisfy the power requirement. Paralleling secondary short storage with the extended storage system can reduce the power losses and size of the central storage [4].

The Lead-acid batteries with high energy density are mainly used with stand-alone DC microgrid applications [5], but it suffers from the short life cycle. On the other hand, characteristic of NiMH batteries is the higher power and energy density with a long-life span than lead-acid batteries. They are entirely safe, and their power output is also free from the batteries state of charge (SOC).

The main concern with the NiMH batteries is their cost and the higher cooling requirement [6]. The supercapacitor has high dynamic performance, a long-life span, and 10 to 100 times higher power density than any other batteries.

Different studies were reported in the literature for energy management of a hybrid energy storage system with supercapacitors and batteries as the energy storage device [7]-[12]. It has been clear from the literature survey that the combined battery and supercapacitor achieve a longer life span, high-power and high energy capability in comparison to the battery alone during pulsating load condition [7]-[9]. The reduction in battery size 
can be achieved up to $64 \%$ when integrated with supercapacitor than ESS having battery alone [13]. A supercapacitor can supply the power for long time intervals and handle high current [14].

The direct integration of the battery and supercapacitor creates a voltage regulation problem at the DC link. In [15] energy management algorithm is proposed for the energy management of RES's and variable load with economical operation feature. Rule-based energy management scheme for a hybrid energy storage system is presented in [16] and [17]; rule base implementation requires ample memory space which is considered a drawback of the proposed approach. In [18] model predictive controller (MPC) based energy management system is implemented; the cost function is the main drawback of the proposed method. The ANN-based control strategy to handle the power-sharing in hybrid storage is presented in [19]; the proposed scheme can constantly maintain the DC bus voltage. The ANN-based energy management for a stand-alone PV system is shown in [20]; the presented method reduced stress on the battery and improve its life span by introducing supercapacitor efficiently. In [21], optimal power flow control in PV Wind hybrid system integrated with a battery is achieved by combining the ANN and Whale optimization algorithm.

The ANN-based control strategy for a HESS consisting of battery-supercapacitor is presented because of the above issues. The main features of the proposed hybrid energy storage control scheme are:

(1) Maintain DC link voltage constant by giving a quick response towards load change or generation change.

(2) Restrict the battery peak current; hence the battery life span increased.

(3) Power flow management of RES's with power quality features.

(4) Parallel connection of energy sources makes the system more reliable as the individual fault cannot interrupt the operation of the whole system.

This paper proposed, a stand-alone hybrid microgrid with a battery and supercapacitor. To extract maximum power from PMSG OT MPPT technique is implemented. The P \& $\mathrm{O}$ algorithm is applied to assure maximum power from the PV panel. When the wind and solar power are sufficient and the generated power exceeds the load's power, first the battery is charged. If the charging current of the battery is too high, then supercapacitor will go into charging mode. If the discharging current of the battery is too high in this situation supercapacitor will shift in discharge mode to supply the load power demand.

Finally, the simulation results taken under different operating condition were verified the effectiveness of the proposed control strategy.

\section{Microgrid configuration}

The proposed hybrid system includes a wind turbine, a PMSG, solar PV modules, an AC/DC converter, two bi-directional DC/DC converter for supercapacitor and NiMH battery, a DC/AC converter, LC filter circuit and a three-phase load. The proposed system configuration is shown in Fig. 1 including HESS. In proposed model ANN based control strategy is used to control the HESS, which regulate the dc bus voltage and make balance of power between demand/supply as shown in Fig. 2.

In Fig. 1 a fully controlled AC/DC bridge rectifier is implemented to extract maximum power form the wind turbine. The gate pulse for the converter is generated by the optimum torque based MMPT technique. A DC/DC converter is used for the photovoltaic system and the gate pulse for the converter is developed by the P \& O MPPT algorithm. The ANN based control strategy is used to regulate DC bus voltage and make balance between load demand and generation. The power from the battery and supercapacitor can flow in the both directions, therefore two bi-directional DC/DC converter is implemented for controlling the power from both energy sources, these bidirectional converters are connected directly to the DC bus. A three phase fully controlled inverter bridge with LC filter circuit is implemented to generate three-phase AC voltage of required magnitude and frequency with low harmonics content. The ANN-based control strategy for power management in a hybrid microgrid is shown in Fig.2. 


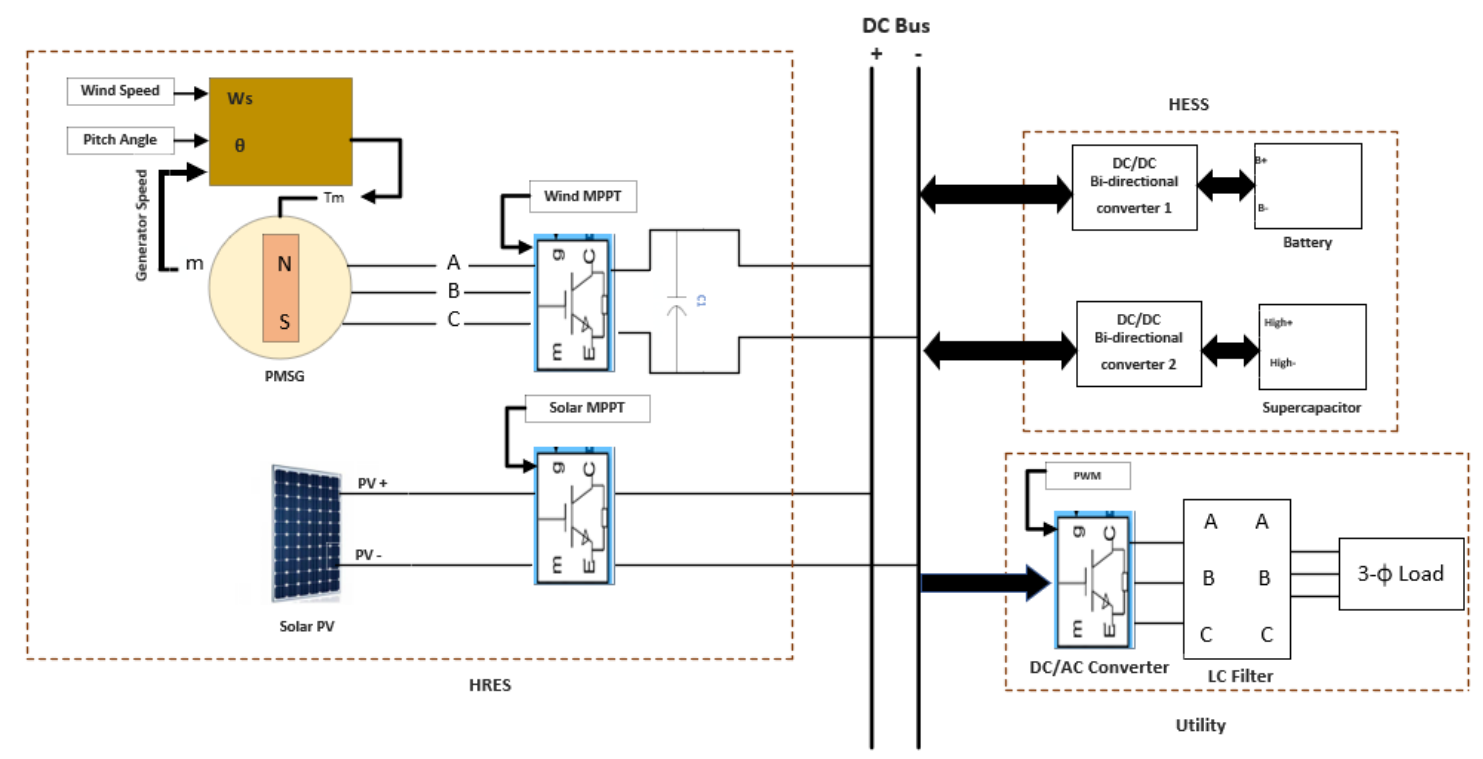

Figure 1 Hybrid microgrid system

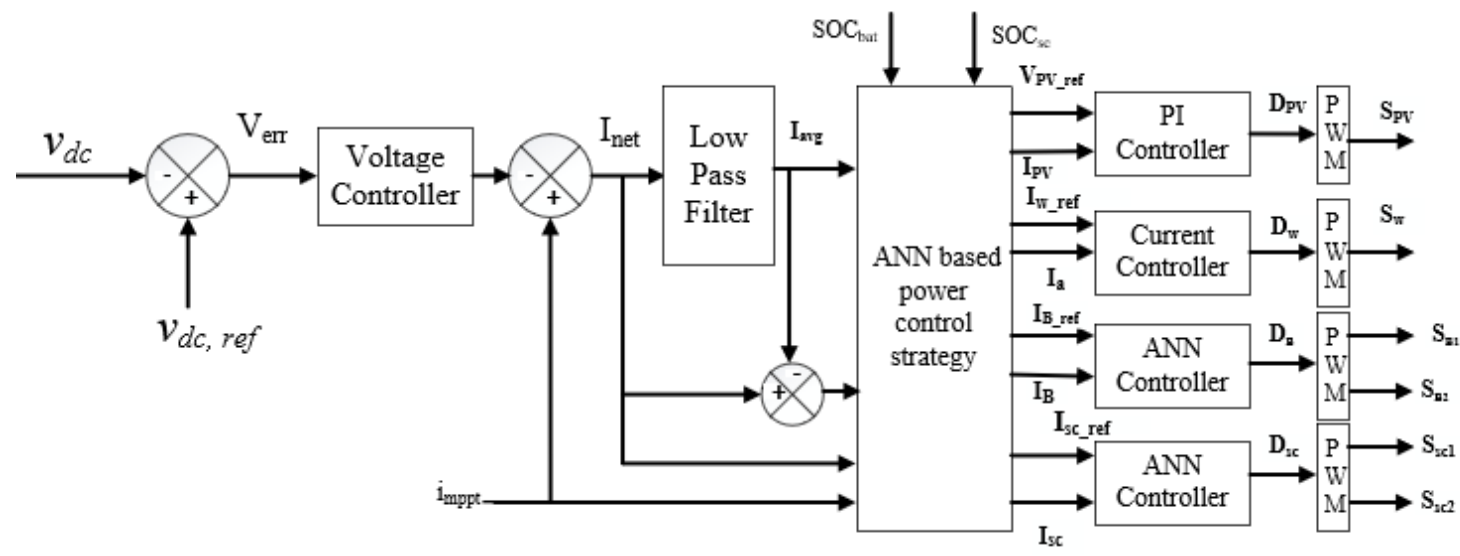

Figure 2 Proposed ANN-based control strategy for management of hybrid storage

\section{Proposed Novel control strategy for Microgrid}

The ANN-based control is quick, robust and stable. It has the potential to improve the power quality and efficiency of the microgrid. The proposed control strategy is intended for the following two conditions: change in the wind velocity and change in solar irradiation.

The following control strategies are proposed for the microgrid to manage the hybrid energy storage system effectively:

(1) An MPPT control strategy is developed to extract maximum power from solar and wind hybrid systems to improve the proposed microgrid's efficiency.

(2) When power generation of the hybrid system is greater than load demand, surplus power is stored in HESS in the following ways. When the charging current of the battery is low, the surplus power generated by RES's charges the battery through bi-directional converter 1. Alternatively, when the charging current surpasses the charging current's set threshold value, then a portion of the surplus power generated will charge the supercapacitor through directional converter 2. During this condition, both the converts will operate in buck mode.

(3) When power generation of the hybrid system less than load demand, then the load power is supplied through the HESS. The battery-SC delivers deficient power in the following ways. When the discharging current of the battery is low, then the difference of the power is given by the battery to the DC bus through the bi-directional converter 1 to fulfil the high-power demand of the load. When the discharging current of the battery surpasses the discharging current set threshold value, then a portion of the deficient power will be given by supercapacitor to the DC bus through bi-directional converter 2. During this condition, both the converts will operate in boost mode. 


\subsection{ANN-based power management}

The proposed ANN based power management aims to control the power-sharing between renewable generation, hybrid storage system and load. The problem defined by:

$$
P_{\text {wind }}+P_{P V}+P_{\text {battery }}+P_{S C}-P_{\text {load }}=0
$$

Where $P_{\text {wind }}$ is the power generated by wind turbine, $P_{P V}$ is the power generated by solar photovoltaic module, $P_{b a t t e r y}$, $P_{S C}$ are the bidirectional power flow from battery and supercapacitor respectively, and $P_{\text {load }}$ is the power demanded by the load. The proposed ANN-based intelligent control strategy measured the battery and supercapacitor reference current by considering the Vdcref voltage and ierror of the hybrid storage system and balancing the power demand. The ANN structure of the multilayer feed-forward neural network is shown in Fig.3.

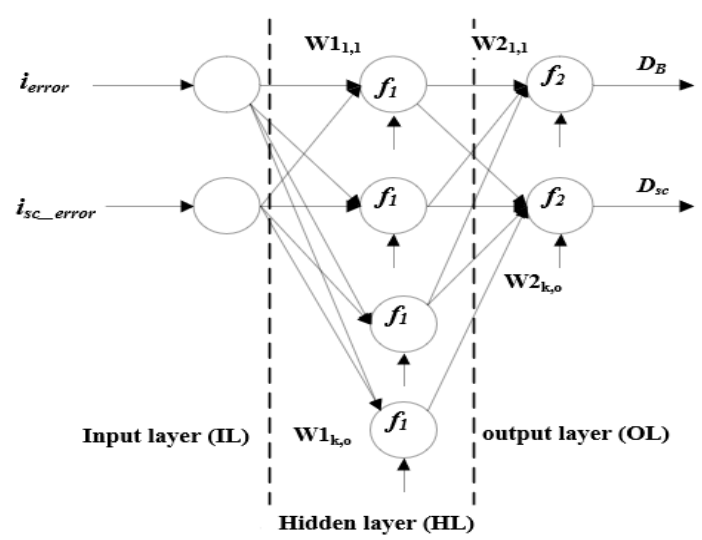

\section{Figure 3 The ANN structure of multilayer feed forward neural network}

In this work, the ANN controller develops a switching signal to the switches of DC-DC converters to connect the battery and supercapacitor. In adaptation law, the ANN weights are updated based on the artificial intelligence algorithm [22] [23].

\subsection{ANN-based voltage control of DC bus}

Fig.4 \& Fig.5 shows the block diagram of the proposed control strategy. Fig. 4 shows that in battery control Vdc and Vdc_ref is compared and the voltage difference is shifted to the ANN controller. While in supercapacitor control as shown in Fig. 5 battery reference current IB_ref and IB were compared and the current difference is compared with Ierror received from battery control to get supercapacitor reference current. This technique gives a fast response to the dynamic changes in microgrid generation and maintains the DC bus voltage constant.

\subsection{Battery control strategy}

The battery energy management strategy is implemented to make the power balance in microgrid. The paper represents battery energy management strategy based on DC link voltage. The control strategy based on the estimation of three parameters i.e., battery state of charge (SOC), battery reference current (IBref) and battery duty cycle (DB) as shown in Fig.4.

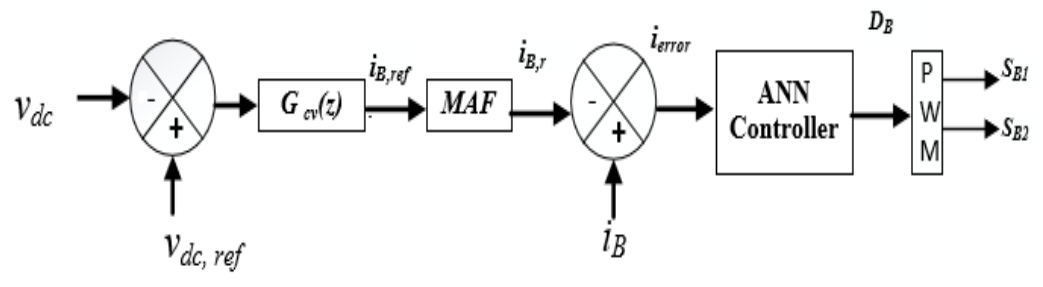

Figure 4 Control strategy for battery converter

During boost mode of the bi-directional converter, the inductor current is given by: 
$\frac{d i_{B}}{d t}=\frac{v_{B}}{L_{B}} D_{B}(t)-\frac{v_{d c}-v_{B}}{L_{B}}\left[1-D_{B}(t)\right]$

After simplifying (2), the battery duty cycle (DB) is derived as under:

$$
D_{B}(t)=\frac{v_{d c}-v_{B}}{v_{d c}}+\frac{L_{B}}{v_{d c}} \frac{d i_{B}}{d t}
$$

In (3) the first part improves the DC bus's voltage regulation against the change in battery voltage. The second part is the variable coefficient, which varies according to change in DC bus voltage and improves the bus's dynamic performance. The moving average filter (MAF) is implemented for the estimation of the average battery current. The battery reference current $\left(i_{B}, r e f\right.$. $)$ is generated by voltage compensator $[\mathrm{G} \mathrm{cv}(\mathrm{z})]$ in the outer DC bus voltage loop. A term $\alpha(v d c, r e f-v d c)$ is added in the outer voltage loop to improve the DC bus's transient response.

$i_{\text {error }}=i_{B}-\frac{1}{T} \int_{t_{0}}^{t_{0}+T} i_{B, r e f} d t$

The main difference between the conventional control method and the proposed strategy is the ability of the inductor current to follow the DC reference voltage generated by the outer voltage loop, which omits the current compensator. Hence the proposed battery control is fast and straightforward.

\subsection{Supercapacitor energy management strategy}

The role of supercapacitor energy management is very important to make DC bus voltage constant and remove the battery's stress during pulsed load. The main focus of the proposed control scheme is on the supercapacitor reference $\left(i_{s c, \text { ref }}\right)$ current generation, which depends on the battery reference $\left(i_{B, \text { ref }}\right)$ and battery error current ( $i_{\text {error }}$ ). The current control of the supercapacitor is achieved by the control variable (Dsc). The proposed control scheme supercapacitor quickly responds to the sudden change in DC bus voltage due to environmental change or load variation. Fig. 5 shows the control strategy for supercapacitor.

$i_{s c, r e f}=\left[i_{B, r e f}-i_{B, r}+i_{\text {error }}\right] \frac{V_{B}}{V_{s c}}$

The supercapacitor reference current $\left(i_{s c, r e f}\right)$ is obtained from the battery reference current ( $i_{B, \text { ref }}$ ) and the gain of

DC bus voltage estimator ( $G_{c v}$ ) is given by (5).

$i_{s c, r e f}=\left[i_{B, \text { ref }}-\frac{2}{T} \int_{t_{0}}^{t_{0}+T} i_{B, r e f} d t+i_{B}\right] \frac{V_{B}}{V_{s c}}$
$i_{s c, \text { error }}=\left[i_{B, r e f}-\frac{2}{T} \int_{t_{0}}^{t_{0}+T} i_{B, r e f} d t+i_{B}\right] \frac{V_{B}}{V_{s c}}-i_{s c}$

The supercapacitor state model during boost mode operation is given by:

$$
\begin{aligned}
& c_{s c} \frac{d v_{d c}}{d t}=i_{s c}\left(1-D_{s c}\right)+\frac{v_{d c}}{R, L_{e q}} \\
& i_{s c}=i_{s c} D_{s c}+c_{s c} \frac{d v_{d c}}{d t}-\frac{v_{d c}}{R, L_{e q}}
\end{aligned}
$$

By solving (8) and (9), the control variable is obtained

$$
D_{s c}=\frac{v_{B}}{i_{s c} v_{s c}}\left[i_{B, n f} \frac{2}{T} \int_{t_{0}}^{t_{0}+T} i_{B, n f} d t+i_{B}\right] \frac{i_{s c, a n r}}{i_{s c}} \frac{c_{s c} d v_{c c}}{i_{s c} d t}+\frac{v_{d c}}{i_{s c} R_{\text {Leq }}}
$$

Where $R_{\text {Leq }}$, is the equivalent load resistance 


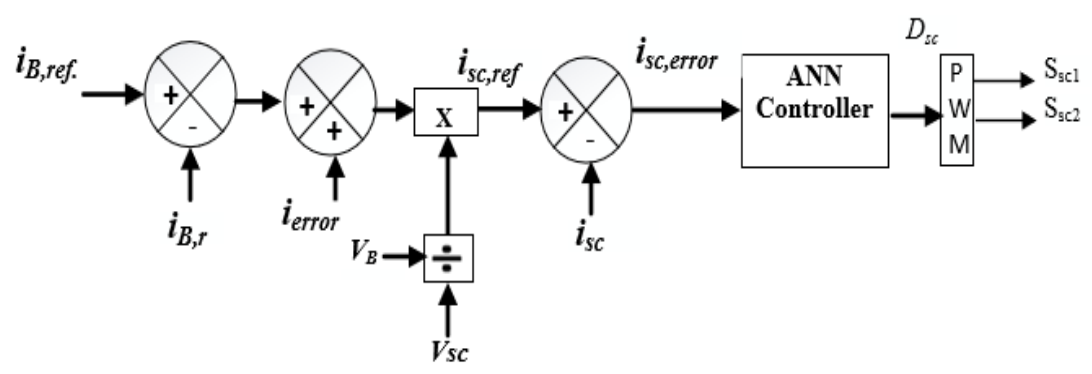

Figure 5 Control strategy for supercapacitor

\section{RESULT \& DISCUSSION}

The proposed system is simulated using MATLAB/Simulink software to verify the presented control strategy's effectiveness. The parameters used during simulation are listed in Table 1.

Table 1 Simulation parameters

\begin{tabular}{|l|l|}
\hline Supercapacitor & Values \\
\hline $\begin{array}{l}\text { Terminal Voltage }\left(v_{s c}\right) \\
\text { Max. Peak current }\left(i_{p}\right) \\
\text { Capacitance }\left(C_{s c}\right)\end{array}$ & $340 \mathrm{~V}$ \\
$10 \mathrm{~A}$ \\
$29 \mathrm{~F}$
\end{tabular}

The normal battery voltage is $300 \mathrm{~V}$, capacity $6.5 \mathrm{Ah}$ and the initial state of charge (SOC) $60 \%$. The DC bus voltage needs to maintain $640 \mathrm{~V}$. The performance of the proposed control strategy for the hybrid energy storage system is investigated under the following cases:

(1) Case-I sudden change in the battery reference current $\left(i_{B}, r e f.\right)$, due to variation in the wind speed.

(2) Case-II sudden change in the battery reference current $\left(i_{B}, r e f.\right)$, due to variation in the solar irradiation

\subsection{Case I: Variation in wind velocity with solar irradiation \& load power is kept constant}

In this case, wind velocity varies from $12 \mathrm{~m} / \mathrm{s}($ at $\mathrm{t}=2.5 \mathrm{~s})$ to $4 \mathrm{~m} / \mathrm{s}(\mathrm{at} \mathrm{t}=3 \mathrm{~s})$, and then come back from $4 \mathrm{~m} / \mathrm{s}$ (at $\mathrm{t}=4.5 \mathrm{~s})$ to $12 \mathrm{~m} / \mathrm{s}$ (at $\mathrm{t}=5 \mathrm{~s})$ during this transition period load power $(5 \mathrm{kw})$ and solar irradiation $(1000 \mathrm{w} / \mathrm{m} 2)$ is kept constant. The waveform of the power from the wind turbine, solar PV module, battery, supercapacitor and load demand is shown in Fig. 6. The battery reference current and SOC are shown in Fig 7 and Fig.8, respectively. The Battery \& supercapacitor voltage and DC bus voltage are shown in Fig. 9 and Fig. 10, respectively. Fig.6 shows that even the wind velocity is varied but also load power of the hybrid microgrid is maintained. During this transient period, power generated by solar-wind hybrid system can't fulfil the load power demand. Therefore, the power balanced is achieved by the battery and supercapacitor. 


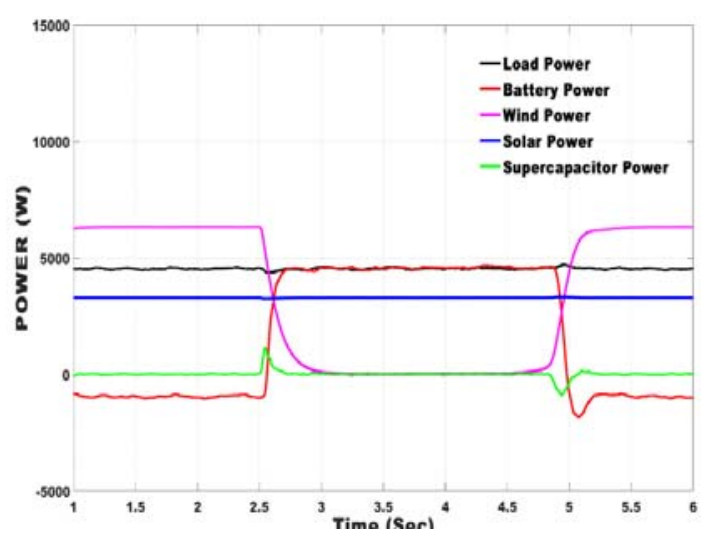

Figure 6 Power balance of hybrid system

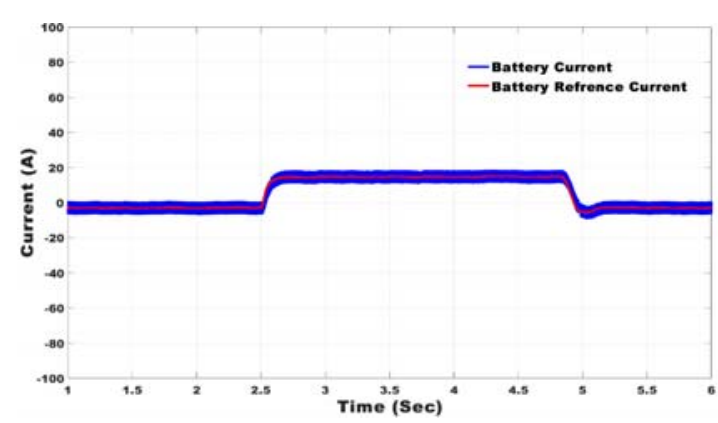

Figure 7 Battery and battery reference current

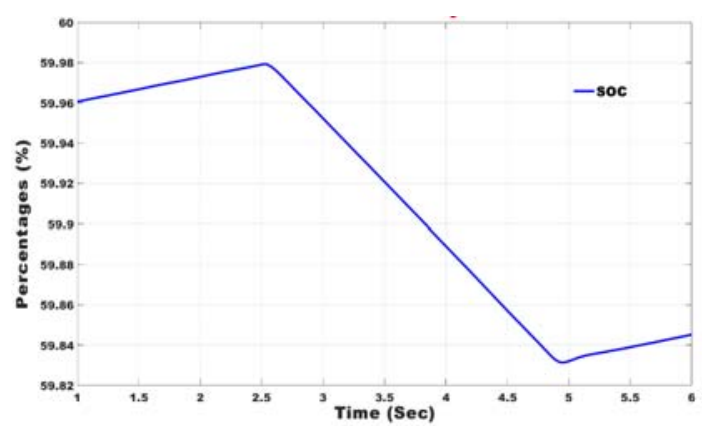

Figure 8 The SOC of the battery

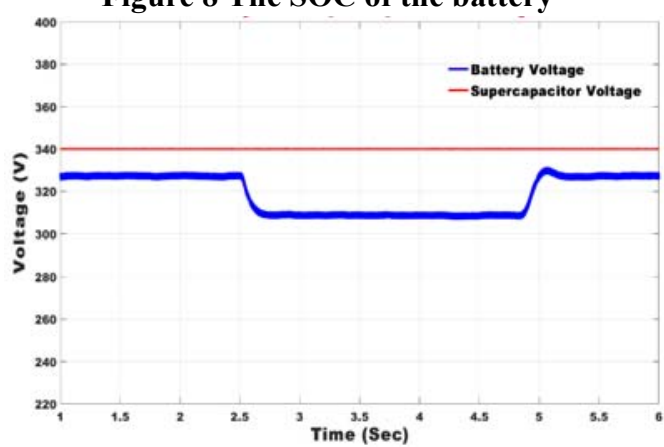

Figure 9 Battery and supercapacitor voltage 


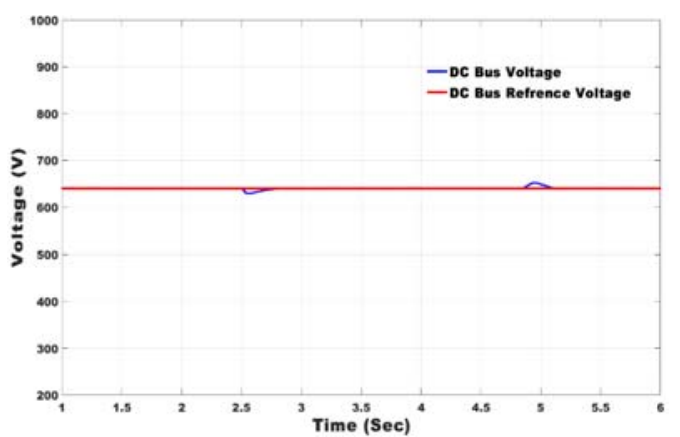

Figure 10 DC bus voltage and DC bus reference voltage

Fig. $6 \& 7$ shows that up to $t=2.5 \mathrm{~s}$, the power generated by the hybrid system is sufficient to supply the load power, and the battery is in charging mode, the SOC of the batter is increasing from its initial value. Between $t=2.5 \mathrm{~s}$ to $\mathrm{t}=4.5 \mathrm{~s}$, the power generated by the hybrid system is not sufficient to fulfil load demand. The battery and supercapacitor achieve the power balance, so the battery is in discharging mode during this time interval, and the SOC of the battery is decreased. After $\mathrm{t}=5 \mathrm{~s}$ the wind velocity is reached at $12 \mathrm{~m} / \mathrm{s}$, and the hybrid generation can supply the load demand.

\subsection{Case II: Variation in solar irradiation with wind velocity \& load power is kept constant}

In this case solar irradiation varies from $1000 \mathrm{w} / \mathrm{m}^{2}$ to $500 \mathrm{w} / \mathrm{m}^{2}$ (at $\mathrm{t}=2 \mathrm{~s}$ ), and then $0 \mathrm{w} / \mathrm{m}^{2}$ between $\mathrm{t}=3 \mathrm{~s}$ to $\mathrm{t}=5 \mathrm{~s}$. After $\mathrm{t}=5 \mathrm{~s}$ solar irradiation increased to $800 \mathrm{w} / \mathrm{m}^{2}$ during this transition period, load power $(5 \mathrm{kw})$ and wind velocity $(12 \mathrm{~m} / \mathrm{s})$ is kept constant. The waveform of the power from the wind turbine, solar PV module, battery, supercapacitor and load demand is shown in Fig. 11. The battery reference current and SOC are shown in Fig 12 and Fig.13, respectively. The Battery \& supercapacitor voltage and DC bus voltage are shown in Fig. 14 and Fig. 15, respectively. Fig.11 shows that power generated by solar PV panel is varied due to change in irradiation. Power generated by the wind turbine alone is insufficient to fulfil the load demand; battery and supercapacitor work together to fulfil load demand.

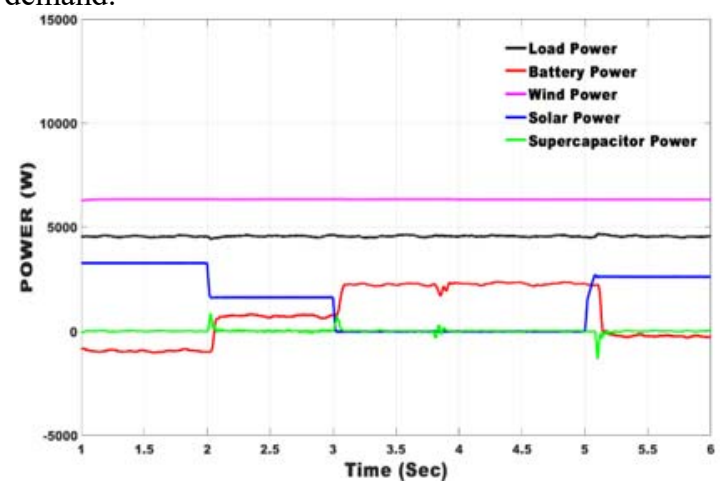

Figure 11 Power balance of hybrid system

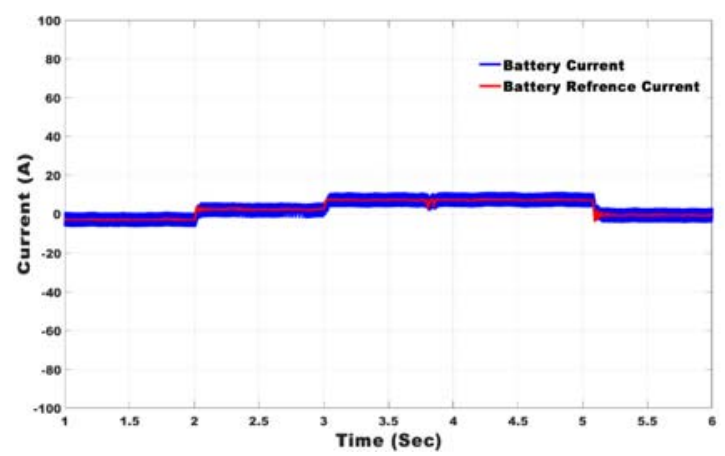

Figure 12 Battery and battery reference current 


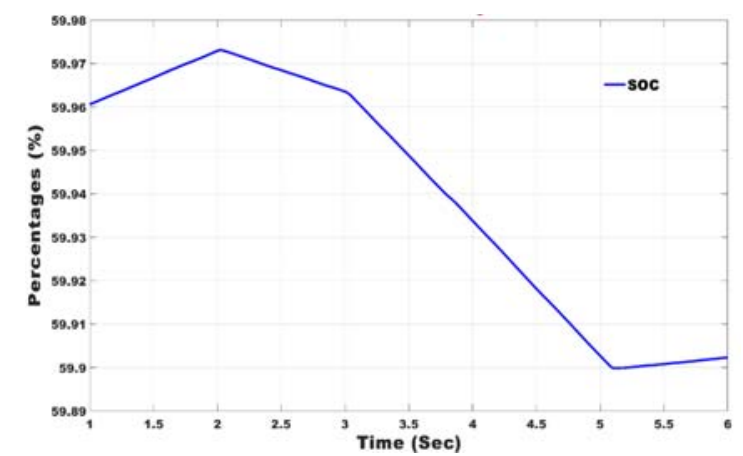

Figure 13 The SOC of the battery

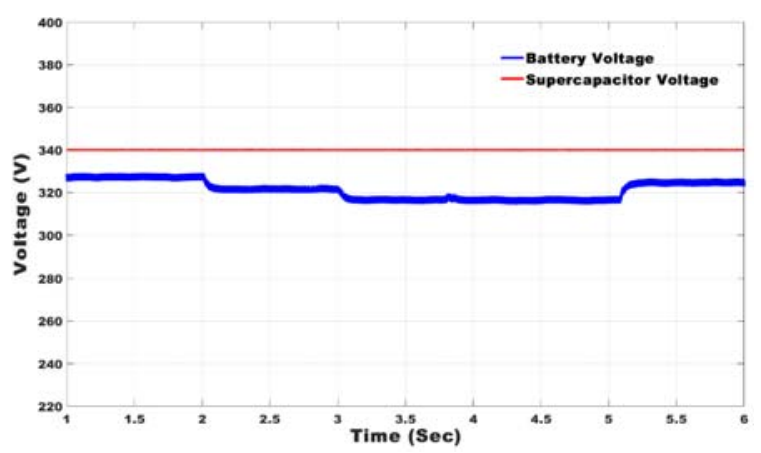

Figure 14 Battery and supercapacitor voltage

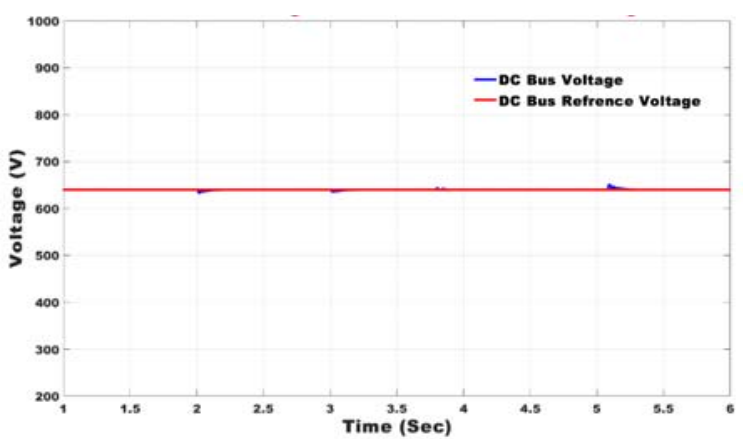

Figure $15 \mathrm{DC}$ bus voltage and $\mathrm{DC}$ bus reference

Fig $11 \& 12$ shows that up to $t=2 \mathrm{~s}$, the power generated by the hybrid system is sufficient to supply the load power, and the battery is in charging mode, the SOC of the batter is increasing from its initial value. Between $\mathrm{t}=$ $2 \mathrm{~s}$ to $\mathrm{t}=5 \mathrm{~s}$ the battery is in discharge because the generated power is less than load demand. After $\mathrm{t}=5 \mathrm{~s}$ the solar irradiation increased to $800 \mathrm{w} / \mathrm{m} 2$, and the battery again switches to charging mode.

The dynamic performance of the proposed system is without and with supercapacitor is shown in Fig. 16 (a) and (b).

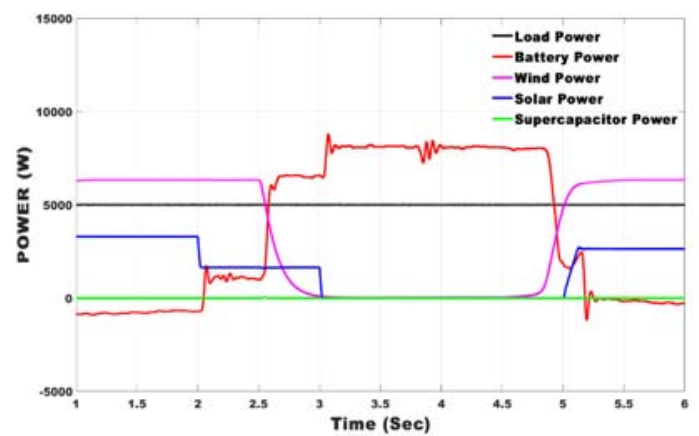

(a) 


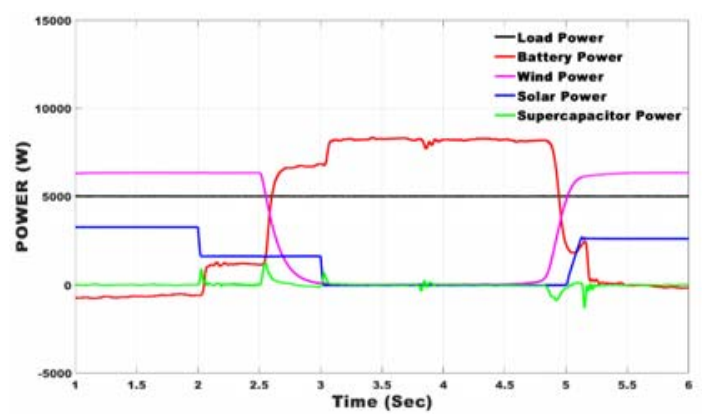

(b)

Figure 16 Performance of the proposed system (a) without supercapacitor (b) with supercapacitor

The dynamics of instantaneous power produced during case III are illustrated in Fig 16. In Fig 16 (a) the DC link voltage is regulated by the battery alone. The sudden change in the DC link voltage due to variation in wind velocity and solar irradiation produced more current stress on the battery hence the battery life cycle gets affected by it and the operation of the proposed system with battery alone affects the battery life span because of large variation in the battery current $\left(\frac{d i_{B}}{d t}\right)$. The dynamics of the proposed hybrid with supercapacitor and battery is shown in Fig. 16 (b). Due to variation in wind velocity and irradiation results in high frequency power surges which are supplied/absorbed by the supercapacitor and the average DC link voltage is controlled by the battery. The high-power density supercapacitor significantly reduces the sudden variation in the DC link voltage. The reduction in the DC link voltage dynamics decreased the current stress on the battery, and therefore the life span of the proposed system may be extended.

\section{CONCLUSION}

ANN-based control strategy for power smoothing of intermittent nature renewable based microgrid with hybrid storage system is presented. The intelligent control strategy is able to regulate DC bus voltage and manage power between PV, wind, load and HESS during the change in microgrid generation due to variation in wind and solar irradiation. The proposed control strategy allows better voltage regulation at DC bus $( \pm 3.01 \mathrm{~V}$ that fulfil the standards $\pm 5 \%$ range) compared to the conventional control strategy. ANN-based control of HESS quickly responds towards the change in the load and generation resulting in to smoothing of power with added advantage of increase in battery life span by reducing instantaneous current stress.

\section{REFERENCES}

[1] P. Thounthong, "Model based-energy control of a solar power plant with a supercapacitor for grid-independent applications," IEEE Trans. Energy Convers., vol. 26, no. 4, pp. 1210-1218, Dec. 2011

[2] A. Etxeberria, I. Vechiu, J.M. Vinassa, H. Camblong, "Hybrid Energy Storage Systems for Renewable Energy Sources Integration in Microgrids: A Review", 9th International Power and Energy Conference, 2010+532-537.

[3] Barote, L., C. Marinescu, and I. Serban. 2010. "Energy Storage for a Stand-Alone Wind Energy Conversion System.” Revue. Roumaine des Sciences Techniques-Serie Electrotechnique et Energetique 55 (3): 235-242, 2010.

[4] W. Li, G. Joós (2008), "A Power Electronic Interface for a Battery Supercapacitor Hybrid Energy Storage System for Wind Applications", Power Electronics Specialists conference IEEE, pp. 1762 - 1768.

[5] El-Ali, A., J. Kouta, D. Al-Samrout, N. Moubayed, and R. Outbib. 2009. "A Note on Wind Turbine Generator Connected to a Lead Acid Battery." Paper presented at the annual meeting for the Society of the 7th International Conference on Electromechanical and Power Systems SIELMEN'09. Ias, i, Romania, October 8 and 9.

[6] John M. German "Hybrid Electric Vehicles" Encyclopedia of Energy, volume 3, 2004.

[7] J. Zheng, T. Jow, and M. Ding, "Hybrid power sources for pulsed current applications," IEEE Trans. Aerosp. Electron. Syst., vol. 37, no. 1, pp. 288-292, Jan 2001.

[8] R. Dougal, S. Liu, and R. White, "Power and life extension of batteryultracapacitor hybrids," IEEE Trans. Compon. Packag. Technol., vol. 25, no. 1, pp. 120-131, Mar 2002. 
[9] J. Brandhorst, H.W. and Z. Chen, "Achieving a high pulse power system through engineering the batterycapacitor combination," in proc. of Applications and Advances conference, Jan 2001, pp. 153-156.

[10] A. Mohamed, V. Salehi, and O. Mohammed, "Real-time energy management algorithm for mitigation of pulse loads in hybrid microgrids," IEEE Trans. Smart Grid, vol. 3, no. 4, pp. 1911-1922, Dec. 2012.

[11]A. Melero-Perez, W. Gao, and J. Fernandez-Lozano, "Fuzzy logic energy management strategy for fuel cell/ultracapacitor/battery hybrid vehicle with multiple-input dc/dc converter," in IEEE Vehicle Power and Propulsion Conference, Dec. 2009, pp. 199-206.

[12] S. Teleke, M. Baran, S. Bhattacharya, and A. Huang, "Rule-based control of battery energy storage for dispatching intermittent renewable sources," IEEE Trans. on Sus. Energy, vol. 1, no. 3, pp. 117-124, Oct. 2010.

[13] A. Etxeberria, I. Vechiu, H. Camblong, J. M. Vinassa, H. Camblong, "Hybrid energy storage systems for renewable energy sources integration in microgrids: a review", In: 2010 Conference Proceedings IPEC, pp. 532537 (2010)

[14]Z. Amjadi and S. S. Williamson, "Prototype design and controller implementation for a battery-ultra capacitor hybrid electric vehicle energy storage system," IEEE Trans. Smart Grid., vol. 3, no. 1, pp. 332- 340, Mar. 2012.

[15] A. Mohamed, V. Salehi, and O. Mohammed, "Real-time energy management algorithm for mitigation of pulse loads in hybrid microgrids," IEEE Trans. Smart Grid, vol. 3, no. 4, pp. 1911-1922, Dec. 2012.

[16]A. Melero-Perez, W. Gao, and J. Fernandez-Lozano, "Fuzzy logic energy management strategy for fuel cell/ultracapacitor/battery hybrid vehicle with multiple-input dc/dc converter," in IEEE Vehicle Power and Propulsion Conference, Dec. 2009, pp. 199-206.

[17] S. Teleke, M. Baran, S. Bhattacharya, and A. Huang, "Rule-based control of battery energy storage for dispatching intermittent renewable sources," IEEE Trans. on Sus. Energy, vol. 1, no. 3, pp. 117-124, Oct. 2010.

[18]B. Hredzak, V. Agelidis, and M. Jang, "A model predictive control system for a hybrid battery-ultracapacitor power source," IEEE Trans. Power Electron., vol. 29, no. 3, pp. 1469-1479, Mar. 2014.

[19]Dong, Weizhen, Shuhui Li, and Xingang Fu. 2018. "Artificial Neural Network Control of a Stand-alone DC Microgrid." In 2018 Clemson University Power Systems Conference Proceeding PSC, pp.1-5, Sept. 2018.

[20] Faria, João, José Pombo, Maria Calado, and Sílvio Mariano. "Power Management Control Strategy Based on Artificial Neural Networks for Standalone PV Applications with a Hybrid Energy Storage System." Energies 12 (5): $902,2019$.

[21] Venkatesan, Karunakaran, and Uma Govindarajan. "Optimal Power Flow Control of Hybrid Renewable Energy System with Energy Storage: A WOANN Strategy." Journal of Renewable and Sustainable Energy 11 (1): 015501,2019 .

[22] R.D. Brandt, F. Lin, "Adaptive interaction and its application to neural networks" Information Sciences 121 (1999) 201-215.

[23]P. Singh, J.S. Lather, "Artificial Neural Network-Based Dynamic Power Management of a DC Microgrid: A Hardware-in-loop Real time verification" International Journal of Ambient Energy, pp.1-19, Jan. 2020. 